nearly the end of the year, when she told me that the pain in the abdomen was excruciating and that it recurred every day; she said it was associated with severe cramp in the limbs, especially in the legs and thighs, and that at night she was kept awake by the pain. Vomiting of large quantities of fluid occurred daily and she was steadily losing weight and strength. Her symptoms begun in 1888 and she had lost 2 st. in weight between that year and 1895. On Dec. 14th, 1895, I opened the abdomen and found the pylorus adheren to the gall-bladder, liver, and abdominal walls, and it was so much thickened as to form a distinct tumour. Pyloroplasty was performed after the adhesions had been separated. Recovery was uneventful and satisfactory in every way and she returned home within the month. She never had any return of the tetanic symptoms, and a report sent to me in March was to the effect that she had gained flesh and was well. The further history of the patient is not germane to the present paper. It will therefore suffice to say that in July, 1896, I saw her again, when she complained of stomach symptoms, but there was not much loss of flesh. Later the vomiting, loss of flesh, and well-marked stomach splash showed that the pyloric trouble had recurred. I performed gastro-enterostomy a month ago as I found a distinct tumour of the pylorus, which I believed to be simple inflammatory induration and not malignant, otherwise I should have excised the pylorus. The patient has made a good recovery and has returned home. The interesting point in her case is that there has never been any return of the painful cramps in the limbs since the first operation.

Though tetany occurs apart from gastric dilatation-for instance in children during teething, when it is frequently associated with gastro-intestinal disorders and not infrequently merges into general convulsions, and in other conditions apart from stomach disorders-yet tetany or painful muscular spasms of a serious character are so frequently associated with that condition that one cannot ignore the association as being merely accidental. It is curious that I have never seen the symptom in other than dilatation due to simple causes, such as adhesions to the pylorus, gallbladder or liver, or in stricture of the pylorus due to the cicatrisation of ulcers. I have never seen it in simple unobstructive dilatation or in dilatation due to cancer of the pylorus, though Dr. Trevelyan gives single examples of its association with both in his paper.

The immediate cause of tetany is perhaps beyond the scope of a surgical paper, but as my views are based on clinical experience they may be worth relating. I have noticed that the exacerbations of the tetanic state, especially in the first case related, were always associated with a painful contraction of the stomach, and that when the wave of contraction had reached the pylorus, which was previously incapable of being felt, it formed a distinct hard tumour. The abdominal pain then became very intense and the tetanic cramps in other muscles came on, or if already present became intensified. From this sequence of events I have come to the conclusion that the cause of the tetany is a double one-(1) the absorption of some poison from the dilated stomach which increases the excitability of the nervous system and (2) a reflex effect produced by the painful contraction of the pylorus. The practical outcome of my paper is that where tetany is, or its allied conditions are, associated with gastric dilatation surgical treatment is well worth considering before the symptoms become so serere as to lead to the almost hopeless condition described in the report of some of the fatal cases.

Leeds.

\section{THE USE OF MORPHIA IN CARDIAC DISEASE. ${ }^{1}$}

BY F. S. TOOGOOD, M.D. LoND.,

MEDICAL SUPERLNTENDENT OF THW LEWISHAM INFIRMARY.

BEFORE studying the clinical effect of morphia in diseases of the heart let us first consider what effect it has upon the heart and circulation in health. When a full dose of morphia is injected the first thing noted is some increase in the pulse-rate; this is effected partly through the cardiac centre and partly through the ganglia in the heart-substance. Then

1 A paper read before the West Kent Medico-Chirurgical Society on
A pril 1st, 1898. succeeds a period when the heart-beats diminish in frequency due to the stimulation of the vagus. If a sufficiently large dose be given this stimulation is succeeded by a period of depression or paralysis of the vagus which is shown by an increased frequency of the pulse due to the loss of balance between the inhibitory action of the vagus and the accelerator fibres. In the majority of cases, however, the intrinsic ganglia of the heart have ere this become paralysed themselves, so that they are unable to take advantage of the withdrawal of the inhibitory influence of the vagus, and so there is a persistence of the slow pulse, which gradually gets weaker and weaker until death ensues.

The action upon the vessels appears to be depressing from the first. The one period which physiologically suggests that morphia might be beneficially used in the treatment of cardiac disease is in the stage where the vagus is stimulated and the heart-beats are diminished in frequency. In the first instance I approached the subject entirely from the clinical side, and it was not until the treatment which had been begun in despair had proved of great benefit in several cases that I sought a physiological basis for that which is, I think, a clinical fact. Those books to which I have access universally agree in condemning the routine administration of morphia in cardiac disease, although most of them record the bald fact that it is occasionally useful. I have little to offer beyond the bare recital of the cases treated, but before considering these let me briefly glance at the antion of the drug upon the kidneys, as it was here that I apprehended the greatest danger.

Of all the lessons which were hammered into me during my hospital career none was more persistently driven home than the fact that it is extremely dangerous to administer morphia in kidney disease or derangement; and as in an imperfectly working heart there is nearly always associated. renal trouble, either in the shape of diminution in the amount of urine excreted or in the presence of albumin and. diminution of the amount of urea and other excretives, so it may be imagined that I watched the quantity and quality of the urine passed by the patients under observation with much interest. Morphia can be detected in most of the secretions : a large proportion is excreted in the bile. It can also be found without much difficulty in the urine. The action of morphia is to diminish the amount of urine passed, to render probable the re-absorption of the drug from the clulled sensibility of the bladder, while in those cases where there is diminished excretory power of the kidney due to disease the danger of retention and accumulation of the drug on the system is sufficiently alarming.

I was first led to try the administration of the drug in those distressing cases of heart-disease (mainly of mitral incompetence) where the exhibition of digitalis and its allies, strophanthus and convallaria, appears to do nothing more. than excite persistent romiting and where the stomach retains. practically nothing, where the heart is extremely irritable and irregular in rhythm and the pulse in volume, where often an ever-present dyspncea renders the condition of the patient intolerable from exhaustion and from want of sleep, and where there may also be œdema from a failing circulation and a scanty amount of albuminous urine. In these cases $\mathbb{I}$ have seen the hypodermic injection of morphia effect the most gratifying results. The pulse has become steady, strong. and regular, the cdema has disappeared, the dyspncea has been relieved, and the urine, instead of being scanty, highcoloured, of high specific gravity, and containing albumin, has become normal in amount and character and the albumin has become much less or has entirely disappeared.

CASE 1.-A man, aged fifty years, was seen by me in consultation in June, 1897; he had been confined to his bed for two months and had been unable to go to business for six months. He was suffering from urgent dyspnœea which had prevented his sleeping for many days. His legs were cedematous and his urine was scanty, loaded with urates, and it contained one-tenth albumin. His pulse was small, easily compressible, 120 to the minute, and irregular in time and rolume. His heart was enlarged, the apex bea occurring in the sixth interspace 1 in. outside the nipple line. There was a distinct systolic murmur heard best over the aortic area. Erery drug which had ever been suggested as of use in cardiac cases had been tried and had proved of no avail. I suggested hypodermic injections of $\frac{1}{4} \mathrm{gr}$. of tartrate of morphia and the effect was marked from the first. He siept quietly and comfortably, the heart gradually came down to 80 beats in the minute, the urine increased to $70 \mathrm{oz}$., the albumin cleared up, and the odema disappeared. "The 
dyspncea varied a good deal and was from the patient's point of view the most troublesome symptom, but he was now free from it except slight paroxysmal attacks when the effect of an injection was wearing off. He gradually improved in general health and two months after the commencement of the treatment was able to take short walks in the neighbourbood and to resume most of his former occupations.

CASE 2.-This patient was a man, aged thirty-two years, a labourer, formerly a soldier, who was admitted to the Lewisham Infirmary from the casual ward on Oct. 5th, 1896, complaining of dyspnoea and pain in the heart. On examination he was found to have his apex beat in the nipple line in the fifth interspace, and to have a reduplication of the first sound and a diastolic murmur well heard at the base and conducted down the sternum. The pulse-beat was of the typical water-hammer character. The urine was of specific gravity 1020, acid and clear, and contained no albumin and no sugar. There was a history of rheumatic fever seven years ago. Under rest and digitalis he recovered his usual state of health, but on Oct. 21st of the following year he had a severe attack of anginal pain and dyspncea which, unlike some of his previous attacks, did not yield to liquor glonoini or to amyl nitrite. It, however, was relieved by a mixture of 10 minims of liquor morphix and $1_{2}^{\frac{1}{2}}$ minims of liquor atropiæ sulphatis every four hours. These anginal attacks now began to recur more frequently but were not very severe and were always relieved speedily by the morphia mixture and in the intervals he was able to get about and to assist in the duties of the ward. On Nov. 1st I find a note that the liver and spleen could be distinctly felt below the ribs. From this time he took to his bed and became progressively weaker and thinner. On Dec. 8th a severe anginal attack necessitated the injection of $\frac{1}{4}$ gr. of morphia which at once relieved him. Although he took a fair amount of nourishment his emaciation became extreme; an occasional injection when he had any return of the pain kept him absolutely comfortable and he died from sheer asthenia on Dec. 12th, 1897 . In this case I claim that morphia succeeded in relieving the anginal attacks when everything else had failed; that it had no bad effect but on the contrary always left him better than it found him ; that it rendered his last weeks comfortable and gave him an easy and painless departure instead of an agonising end, without in any way shortening his days.

CASE 3.-A man, aged fifty-one years, a labourer, was admitted to the Lewisham Infirmary on Jan. 6th, 1897, complaining of pain in the chest in the cardiac area off and on for nine months and of dyspnoea for over a year. On examination his apex beat was found to be $2 \frac{1}{2}$ in. below the nipple and just outside the nipple line; there was also a loud aortic systolic and diastolic murmur. Under rest, stimulants, and cardiac tonics, including digitalis and strychnine, he gradually grew worse; he conld not sleep and he vomited incessantly, and his condition was considered absolutely hopeless. On Feb. 3rd 15 minims of liquor morphiæ were added to his mixture and from that time he steadily improved; the morphia required to be increased once or twice and an occasional hypodermic injection of the same drug was used in anginal attacks, but he steadily improved, contracted a fresh lease of life, and took his discharge on June 5th, 1897, with his heart thoroughly compensated and doing its work well.

CASE 4.-A woman, aged thirty-four years, was admitted to the Lewisham Infirmary on July 28th, 1897, complaining of shortness of breath and of great weakness. There was a history of rheumatic fever twenty-four years ago. She was suffering from urgent dyspncea, constant distressing cough, and had codema of both legs. The apex beat was in the seventh interspace just outside the nipple line, The pulse was very irregular in force and frequency, over 120, and could scarcely be counted. There were well-marked systolic and presystolic murmurs. There were râles and rhonchi all over the chest. The urine was of specific gravity 1024, acid, very dark, and scanty, was one-third albumin, and contained no blood and no sugar. Rest, digitalis, and stimulants did not afford any relief and on August 3rd persistent vomiting set in which the omission of the digitalis did not relieve. On August 12 th 10 minims of liquor morphiæ were given every four hours. The effect was marked from the first; the vomiting ceased and the urine became more copious, increasing steadily from $10 \mathrm{oz}$. to from $60 \mathrm{oz}$. to $70 \mathrm{oz}$. in the twenty-four hours. The albumin gradually decreased, and on Sept. 11th it disappeared altogether. It was thought that this might have nothing to do with the morphia, so on several occasions the morphia was withheld, but this was invariably followed by a marked diminution in the quantity of urine and by an increase in the amount of albumin. I will not weary you by a recapitulation of a convalescence. A too early withholding of the morphia caused a relapse which at once cleared up on the renewal of the dose and after a prolonged and careful probationary course of exercise she took her discharge on March 19th with no symptoms and with her heart presumably compensated for a time but still acting irregularly and with the murmurs quite as distinct as before. CASE 5. - A woman, aged twenty-four years, was admitted to the Lewisham Infirmary on Dec. 2nd, 1897, complaining of " pains in the heart." She was thin, anæmic, and slightly yellow. The apex beat was in the fifth interspace and gave no evidence of hypertrophy or dilatation. The action of the heart was irregular and quick and the pulse was easily compressible. There was a loud mitral systolic murmur heard. The first sound was suggestive of mitral obstruction. Rest and iron were prescribed. On the 22nd, there being: no improvement, 5 minims of tincture of digitalis were ordered. A slight improvement followed, but on Feb. 10th her condition, which had been very carefully watched, became very alarming. The action of the heart became tumultuous, there was great cardiac pain, and a distinct presystolic murmur developed. $4 \mathrm{oz}$. of stimulant in the twenty-four hours were ordered. On the 12th the pulse was almost imperceptible and the patient was in a state of collapse and apparently dying. She was only passing $16 \mathrm{oz}$. of urine in the twenty-four hours and was vomiting incessantly. The digitalis was omitted. A hypodermic injection of $\frac{1}{4}$ gr. of morphia was given every twelve hours and the patient did what she had not done for many days-viz., she slept soundly. She immediately began to improve ; the vomiting ceased, the urine became normal in amount, and the tumultuous action of the heart subsided. The presystolic murmur became less and less pronounced and the action of the heart more and more regular, until by March 17th the presystolic murmur had entirely disappeared and the heart's action was absolutely regular, although a well-marked mitral systolic murmur remained, and the patient was to all intents and purposes well.

I have chosen these 5 cases as being fairly good examples of the beneficial results of this method of treatment, although many more might be cited, and I may say here that I have had no accident. That morphia in large doses is a cardiovascular depressant is well known, but its sedative and soothing effects upon irritable conditions of other organs are so well recognised that I am inclined to think that the undoubtedly beneficial results in cardiac disease are due to its action upon the nervous apparatus of the cardio-vascular system, both central and local, bringing rest to an overstrained organ and allowing it the chance of developing its recuperative power.

Lewisham, S.E.

\section{DEATH FROM DIABETES MELLITUS IN WHICH THAT DISEASE GAVE NO PREMONITORY SYMPTOMS.}

\section{BY T. WILSON PARRY, M.A., M.B. CANTAB.}

A MESSAGE was brought to me at 8 o'clock on the morning of Nov. 9th that a woman living in a village some five miles from here had suddenly fallen down while in the act of dressing at 6 A.M. and could not "get her breath"; would I come at once? I started with the least possible delay and arriving at the house found that the patient, a woman sixtyeight years of age, had suddenly fallen, as my messenger had informed me, while dressing, without any previous warning of any kind and had been in a comatose state ever since. On examination I found the pupils to be contracted and only very slightly, if at all, reacting to light; the reflex was entirely abolished. All the limbs were flaccid and the knee-jerks were absent. I immediately put my stethoscope to the heart expecting to find an accentuated second sound (superficially diagnosing the case-from the suddenness of its onset, the age of the patient, and her previous apparently 